Significant Findings Statement

Snow Crystal Orientation Effects on the Scattering of Passive Microwave Radiation

Question: In the microwave portion of the electromagnetic spectrum, does it make a difference in terms of how much energy is scattered by snow crystals, whether or not they have a particular orientation in regards to each other? Put in another way, in calculating the amount of energy that is transferred from the ground, through the snowpack, can it be assumed that all of the crystals in a snowpack are randomly oriented?

Approach: Use a particle scattering model to simulate the scattering of microwave radiation for crystals having different orientations.

Significance: A discrete dipole scattering model was used to measure the radiation scattered by snow crystals having different orientations. Findings imply that the orientation of the snow crystal, in comparison to the size of the crystal and the spacing between crystals, plays an insignificant role in scattering microwave energy in the $35 \mathrm{GHz}$ region of the spectrum. Therefore, the assumption in radiation transfer approaches, where snow crystals are modeled as random scatterers, is adequate to account for the transfer of microwave radiation emanating from the ground and passing through a snowpack.

Relation to MTPE science plan: Land surface variability and water process studies (snow hydrology). 


\title{
Snow Crystal Orientation Effects on the Scattering of Passive Microwave Radiation
}

\author{
J. L. Foster, J. S. Barton*, A. T. C. Chang, and D.K. Hall \\ NASA/Goddard Space Flight Center, Code 974 \\ Hydrological Sciences Branch \\ Laboratory for Hydrospheric Processes \\ Greenbelt, MD 20771 U.S.A \\ phone: 301-286-7096, fax: 301-286-1758 \\ e-mail: jfoster@glacier.gsfc.nasa.gov \\ *General Sciences Corporation, Greenbelt, MD 20770
}

\begin{abstract}
For this study, consideration is given to the role crystal orientation plays in scattering and absorbing microwave radiation. A discrete dipole scattering model is used to measure the passive microwave radiation, at two polariztions (horizontal and vertical), scattered by snow crystals oriented in random and non random positions, having various sizes (ranging between $1 \mu \mathrm{m}$ to $10,000 \mu \mathrm{m}$ in radius), and shapes (including spheroids, cylinders, hexagons). The model results demonstrate that for the crystal sizes typically found in a snowpack, crystal orientation is insignificant compared to crystal size in terms of scattering microwave energy in the $8,100 \mu \mathrm{m}$ $(37 \mathrm{GHz})$ region of the spectrum. Therefore, the assumption used in radiative transfer approaches, where snow crystals are modeled as randomly oriented spheres, is adequate to account for the transfer of microwave energy emanating from the ground and passing through a snowpack.
\end{abstract}

\section{Introduction}

Although snow and ice crystals may have a preferred orientation as they fall through the air on their way to the ground, once on the surface, their orientation with respect to a particular axis is most likely to be random. Processes such as sintering, compaction, and saltation act to prevent the crystals from being aligned in a like fashion. Nevertheless, because crystals within a given layer of the snowpack were formed and subsequently accumulated at nearly the same time, their physical characteristics, including their size, shape, density, and how they are oriented, are expected to be more similar to each other than they are to crystals in adjacent layers. 
Advances in particle scatter modeling and snow crystal collecting techniques have permitted much more detail to be learned about the physical characteristics of individual snow grains and about the redistribution of energy by these grains. By learning as much as we can about the physics of snow and how crystals interact with electromagnetic energy, we will be better able to accurately and reliably estimate the total area and volume of snow for a given drainage basin or climatic region. Knowing more about these values will then permit us to improve forecasts of snowmelt runoff and streamflow, and thus allow us to more confidently gage both the water and energy balance of a given area.

Although it is the volume of all of the snow crystals which is largely responsible for the microwave signal (Chang et al., 1976), it is not known whether or not the orientation of individual crystals has any effect on increasing the scattering or lessening the scattering of this signal. Most of the attention in algorithm development has been directed towards the effects of snow crystal size on scattering microwave energy, and some work has been devoted to the effects of crystal shape on microwave scattering (Foster et al., 1999). However, crystal size alone does not account for all of the scattering or energy redistribution.

Presently, a number of microwave algorithms are available to evaluate and retrieve snow cover and snow depth for specific regions and specific seasonal conditions. For the Chang et al. (1987) algorithm, the lack of precise information about snow crystal size and shape has been compensated for by using an average size of $0.3 \mathrm{~mm}$ (radius), a density of $300 \mathrm{~kg} \mathrm{~m}^{-3}$, an assumed spherical shape for the snow crystals, and the assumption that the crystals scatter 
radiation incoherently and independently of the path length between scattering centers (Chang et al., 1987). It has been demonstrated that if the snow crystal size differs significantly from the assumed average, then poor snow water equivalent (SWE) estimates will result (Chang et al., 1987; Foster et al., 1996). Furthermore, it has been found that the shape of the crystal plays no significant role in scattering microwave radiation (Foster et al., 1997; Foster et al., 1999). However, it has not been known whether a significant error is induced in solving the radiative transfer equations by making assumptions about the orientation of snow crystals in a mature snowpack.

This study is a follow up to the paper on the microwave response to snow crystal shape, which was published in this journal last year (Foster et al., 1999). For the present study, again a particle scattering model is used, but this time to calculate the extinction, scattering and absorption efficiency of crystals having random and non random orientations with both horizontal and vertical polarizations. This information will be valuable for determining whether the orientation of the snow crystal is an important enough parameter to be accounted for in modeling the radiative transfer of microwave energy emanating from below and within snowpacks.

\section{Passive Microwave Radiometry}

The microwave radiation emitted by a snow cover is dependent upon the physical temperature, crystal characteristics and the density of the snow. A basic relationship between these properties and the emitted radiation can be derived by using the radiative transfer approach. Microwave emission from a snow layer over a ground medium consists of contributions from the snow itself and from the underlying ground. Both contributions are governed by the transmission 
and reflection properties of the air-snow and snow-ground boundaries and by the absorption/emission and scattering properties of the snow layers (Foster et al., 1984). If the snowpack is thick (> penetration depth of the wavelength) then it may be treated as a semi-infinite medium and contributions from the ground will not be as important (Chang et al., 1976). Otherwise, volume scattering by the myriad of crystals is the primary mechanism for the redistribution of the emitted microwave energy.

As an electromagnetic wave emitted from the underlying ground propagates through the snowpack, it is scattered by the snow particles in all directions. Consequently, when the wave emerges at the snow/air interface, its amplitude has been attenuated. Dry snow absorbs very little microwave energy, and therefore it contributes very little in the form of self-emission (Ulaby and Stiles, 1981; Foster et al., 1984). Snow crystals are effective scatterers of microwave energy for frequencies greater than $\sim 20 \mathrm{GHz}$. The snow crystals scatter part of the cold sky radiation, which reduces the upwelling radiation measured with a radiometer (Schmugge, 1980). The deeper the snow, the more snow crystals are available to scatter the upwelling microwave energy, and thus it is possible to estimate the depth of the snow and the snow water equivalent. Absorption of microwave energy by dry snow crystals is very small, about $10^{6}$ times smaller than for water in the liquid phase (Ulaby and Stiles, 1981). With increasing free water in snow, and an accompanying increase in the dielectric constant, absorption will begin to dominate over scattering (Hallinkainen, 1989). 


\section{Modeling}

A discrete dipole model (Draine and Flatau, 1994) is used here to approximate the microwave scattering and absorption of an idealized snow crystal having two orientations; random and non random. In this experiment, spheroids, cylinders, and hexagons were modeled having an effective radius (radius of a sphere of equal volume) of $10 \mu \mathrm{m}, 50 \mu \mathrm{m}, 100 \mu \mathrm{m}, 300 \mu \mathrm{m}, 500 \mu \mathrm{m}, 700 \mu \mathrm{m}$, $1,000 \mu \mathrm{m}, 1,300 \mu \mathrm{m}, 5,000 \mu \mathrm{m}$, and 10,000 $\mu \mathrm{m}$. The discrete dipole scattering (DDSCAT) model employed here is a Fortran program that calculates scattering and absorption of electromagnetic radiation by arbitrary targets using the discrete dipole approximation (DDA). In this approximation, the targets are replaced by an array of point dipoles. See Draine (1988) and Foster et al. (1999) for more details concerning the DDSCAT model.

For this study, the wavelength selected was 8,100 microns $(0.81 \mathrm{~cm})$, corresponding to $37 \mathrm{GHz}$. Previous work has shown (Chang et al., 1987), that for snowpacks less than a meter in depth, more information about the SWE can be derived when using a frequency of about $37 \mathrm{GHz}$ than when using higher or lower frequencies. A refractive index of 1.78 is used for the real part of the refractive index of ice and 0.0024 is used for the imaginary part (the refractive index is the square root of the dielectric constant). The true thickness of a deposit is not required for emission boundary conditions; scattering or absorption results from the array of point dipoles.

The incident radiation is always assumed to propagate along the $\mathrm{x}$ axis. Two vectors (a1 and a2) are assumed to be embedded within the target; a2 is perpendicular to a1. For the case of a $9 \times 6 \times$ 3 rectangular array, the vector a1 is along the long axis, and the vector a2 is along the intermediate axis. The target orientation is set by the angles BETA, THETA and PHI. The polar 
angles THETA and PHI specify the direction of al with respect to the incident radiation. The target is assumed to be rotated around al by an angle BETA. In this study, two cases were examined: a randomly oriented case, where BETA, THETA, and PHI are all allowed to vary between 0 and 360 degrees and the result is averaged over that range; a non random case, where BETA and PHI are held constant at $0^{\circ}$, and THETA is permitted to vary from $0-90^{\circ}$. The model allows for the specification of a general elliptical polarization for incident radiation. However, for this study, two linear polarizations, parallel to the horizontal and vertical axes, were used. Scattered intensities are computed for two scattering planes at intervals of 30 degrees in the scattering angle theta.; $\mathrm{phi}=0$ for the $\mathrm{x}-\mathrm{y}$ plane, and $\mathrm{phi}=90$ for the $\mathrm{x}-\mathrm{z}$ plane (Draine and Flatau, 1994)

\section{Results and Discussion}

Tables 1, 2 and 3 show extinction, absorption and scattering for non random as well as random crystal orientations (spheroids, cylinders and hexagonal prisms) having either horizontal or vertical polarizations. Figures 1, 2 and 3 (not shown here) present what the tables convey in graph form.

Looking at Table 1, for non randomly oriented and horizontally polarized crystals having an effective radius of $300 \mu \mathrm{m}$, and with the above BETA, THETA and PHI constraints, the average scattering is equal to $1.44 \times 10^{-3}$, the average absorption is equal to $9.68 \times 10^{-3}$, and the extinction efficiency is equal to $1.11 \times 10^{-2}$ ( $\mathrm{Q}$ extinction $=\mathrm{Q}$ scattering $+\mathrm{Q}$ absorption). For the randomly oriented, horizontally polarized spheroids, scattering, absorption and extinction are 
$1.43 \times 10^{-3}, 9.66 \times 10^{-3}$ and $1.11 \times 10^{-2}$, respectively. There is virtually no difference between the randomly and non randomly oriented spherical crystals.

Looking at each of the three Tables, it can be observed that regardless of the size, the shape or the polarization of the crystal, only very small differences exist between the randomly and non randomly oriented crystals. For instance, when comparing the scattering of non randomly oriented spheres to cylinders, the amount of scattering is similar, no matter what the particle size. The cylinders scatter minutely more amounts of radiation than do the spheres. For randomly oriented crystals, the scattering differences between spheres and cylinders are even smaller. However, whereas for the non randomly oriented cylinders a slight difference exists in scattering between the $\mathrm{H}$ and $\mathrm{V}$ polarizations, there is no difference in scattering between the $\mathrm{H}$ and $\mathrm{V}$ polarizations for the randomly oriented cylinders. This is also true for the hexagonal prisms. Also, note that for each crystal shape, regardless of the orientation, the $\mathrm{V}$ polarization has the same scattering values for all but the largest crystal sizes.

It should be pointed out that for the largest crystals $(10,000 \mu \mathrm{m})$, extinction may actually decrease. This is because when the particle size is greater than the wavelength $(8100 \mu \mathrm{m})$, extinction no longer increases but rather oscillates (Ulaby et al., 1981). Calculations of the attenuation cross sections of large ice and water spheres have shown that the normalized attenuation cross section increases up to a size parameter $(\alpha)$ of 1 , and from there decreases to a size parameter of 5 (Atlas and Wexler, 1963; Battan, Browning and Herman, 1970). 
It is reasonable to expect that freshly fallen snow is more likely to have preferred crystal orientations than do older snow grains which due to settling, melt and refreezing have been repositioned. In some cases, the structure of the snowpack has been shown to exacerbate the differences between the vertically and horizontally polarized microwave data. For example, Hall et al. (1984) found that where the snowpack has undergone metamorphism, horizontally polarized data are better correlated to snow depth and SWE than are vertically polarized data. The vertically-polarized brightness temperatures at $37 \mathrm{GHz}$ for snow covered land has been shown to be more sensitive, or to vary more diumally, than horizontally polarized brightness temperatures (Hallikainen, 1989). Walker and Goodison (1993) have used the polarization difference at $37 \mathrm{GHz}$ to discriminate wet snow from snow free land. Ice lenses and metamorphosed snow layers are horizontal media, which seem to influence vertically-polarized data more than the horizontally polarized data. From the tables, non randomly oriented crystals, do show small polarization differences compared to the randomly oriented crystals, but again, these modeled differences are very small.

For the visible wavelengths, how ice crystals are aligned as they fall through the air is strongly related to how light is refracted and reflected to an observer on the ground. Ice crystals may become oriented by aerodynamic forces as they fall through the atmosphere. If this happens, a collection of stellar plate crystals, for instance, is aligned with their faces (a axis) in a horizontal position to the ground while the plate edge is vertical (c axis). If sunlight passes symmetrically through the plane perpendicular to the refracting edge, minimum deviation will occur. The 22 degree minimum deviation of sunlight passing through the 60 degree prism of the hexagonally oriented plates will cause the light to be concentrated in a narrow range of angles, resulting in a 
parhelia or sundogs (bright spots on either side of the Sun, at least 22 degrees away). A grouping of these same plate crystals which show no preferred orientation will instead produce a 22 degree halo around the Sun (Lynch and Livingston, 1995).

With wavelengths longer than visible light, crystal orientation is not a key factor in terms of how much energy is scattered and absorbed in falling snow or in snow on the ground. For the crystal sizes typically found in a snowpack, the effective particle size is so dominant in scattering microwave radiation that the cumulative contribution of other structural features, including orientation, seems to be overwhelmed. Evidence for this has been presented in several studies (Siqueira, 1995, Matzler, 1997 and Foster et al., 1999). In refining the microwave algorithms used to estimated snow depth and SWE, it is necessary to have accurate measurements and or models that consider the effects of all possible sources in scattering and absorbing microwave energy. It is important to know which contributions are critical and which can be ignored. The results presented here using a discrete dipole model show that for scattering, the crystal orientation can be ignored, in terms of the extinction of microwave energy.

Nevertheless, it needs to be remembered that models are only representations which can be used to direct experiments, but their accuracy cannot actually be proved, only disproved (Oreskes, 1994). The mathematical representations are only approximate descriptions of actual processes because the processes are so complex and are based on observations which themselves contain uncertainties. Even if the solutions seem reasonable and reproducible, this does not mean that they are correct. This being said, the discrete dipole model has been consistent with a number of 
physical observations, crystal size and microwave scattering for instance. Thus, this model can be more confidently used to evaluate snow crystal orientation effects and microwave scattering.

\section{Conclusions and Future Plans}

While effective crystal size is strongly related to microwave brightness temperature, it appears from the modeling results of this study that the orientation of snow crystals has a negligible effect in accounting for the transfer of microwave radiation (at $8,100 \mu \mathrm{m}$ ) from the ground through the snowpack. Furthermore, regardless of the shape of the crystal (spheroid, cylinder or hexagonal prism), the polarization effects are only slightly greater for non randomly oriented crystals than for randomly oriented crystals. Thus, the assumption used in radiative transfer approaches, where snow crystals are modeled as randomly oriented spheres, is adequate to account for the transfer of microwave energy emanating from the ground and passing through a snowpack.

\section{References}

Armstrong, R., A. Chang, A. Rango, and E. Josberger, "Snow depth and grain size relationships with relevance for passive microwave studies" Annals of Glaciology, Vol. 17, 171-176, 1993.

Chang, A. T. C., P. Gloersen, T. Schmugge, T. Wilheit, and H. J. Zwally, "Microwave emission from snow and glacier ice" Journal of Glaciology, Vol. 16, 23-39, 1976.

Chang, A.T.C., J.L. Foster and D.K.Hall, "Nimbus-7 SMMR derived global snow cover parameters" Annals of Glaciology, Vol. 9, 39-44, 1987. 
Draine, B., "The discrete dipole approximation and its application to interstellar graphite grains," Journal of Astrophysics, Vol. 33, 848-872, 1988.

Draine, B. and P. Flatau, "Discrete dipole approximation for scattering calculations," $\underline{\text { Journal of }}$ the American Optical Society, Vol. 11, 1491-1499, 1994.

Foster, J. L., D. K. and A. T. C. Chang, "An overview of passive microwave snow research and results" Reviews of Geophysics and Space Physics Vol. 22, 195-208, 1984.

Foster, J., D.Hall, A. Chang, A. Rango, W. Wergin, and E. Erbe, "Observations of snow crystal shape in cold snowpacks using scanning electron microscopy," Proceedings of the IGARSS 1996, Vol. 4, 2011-2013, Lincoln, NE, 1996.

Foster, J., D. Hall, A. Chang, A. Rango, W. Wergin, and E. Erbe, "Snow crystal shape and microwave scattering" Proceedings of the IGARSS 1997, Vol. 2, 625-627, Singapore, 1997.

Foster, J., A. Chang, D. Hall, A. Rango, W. Wergin, and E. Erbe, "Effects of snow crystal shape on passive microwave radiation" Transactions of Geoscience and Remote Sensing (IEEE) (in press).

Goodman, J., B. Draine, and P. Flatau, "Applications of FFT techniques to the discrete dipole approximation," Optical Letters, Vol. 16, 1198-1200, 1991. 
Hall, D. K., A. T. C. Chang, and J. L. Foster, " Polarization responses to snow depth in the midwestern U. S. “ Nordic Hydrology, Vol. 15, 1-8, 1984.

Hallikainen, M., "Microwave radiometry of snow" Advanced Space Research, Vol. 9, No. 1, 267-275, 1989.

Lynch, D. and W. Livingston, Color and Light in Nature , Cambridge University Press, NY, 152-166, 1995.

Matzler, C., "Autocorrelation functions of granular media with arrangement of spheres, spherical shells or ellipsoids" Journal of Applied Physics, Vol. 3, 1509-1517, 1997.

Oreskes, N., K. Shrader-Frechette and K. Belitz, 1994: "Verification, validation and confirmation of numerical models in the earth sciences" Science, Vol. 23, 762-767.

Schmugge, T., "Techniques and applications of microwave radiometry" in Remote Sensing of Geology, edited by B. Siegal and A. Gillespie, John Wiley, New York, Chapter 11, 337-352, 1980.

Siqueira. P. R., K. Sarabandi and F. T. Ulaby, "Numerical simulation of scatterer positions in a very dense medium with an application to the two-dimensional Born approximation" $\underline{\text { Radio }}$ Science, Vol. 30, Number 5, 1325-1338, 1995. 
Ulaby, F. T. and W. H. Stiles, "The active and passive microwave response to snow parameters" Journal of Geophysical Research, Vol. 85, 1045-1049, 1981.

Ulaby, F. T., K. Moore, and A. K. Fung,, Microwave remote sensing: active and passive, Vol. III, Adison-Wesle Publication Co, 1986

Walker, A. E. and B. E. Goodison, "Discrimination of a wet snow cover using passive microwave satellite data" Annals of Glaciology, Vol. 17, 307-311. 


\section{List of Tables}

Table 1 - Extinction, scattering and absorption efficiency for randomly and non randomly oriented spheroid snow crystals having both horizontal and vertical polarizations, as determined using a discrete dipole model.

Table 2 - Same as Table 1 except for cylindrical crystals.

Table 3 - Same as Table 1 except for hexagonal prisms.

\section{List of Figures}

Figure 1 - Plot showing scattering efficiency of spherical water ice particles having both random and non random orientation.

Figure 2 - Same as Figure 1, except for cylindrical particles.

Figure 3 - Same as Figure 1 and 2, except for hexagonal particles. 
Table 1. Extinction, absorption, and scattering efficiency for randomly and nonrandomly oriented spherical snow crystals having both horizontal and vertical polarizations, as determined using a discrete dipole model.

\begin{tabular}{|c|c|c|c|c|c|c|}
\hline \multirow{2}{*}{$\begin{array}{c}\text { Polarization } \\
\text { Size }(\mu \mathrm{m})\end{array}$} & \multicolumn{3}{|c|}{ Horizontal } & \multicolumn{3}{|c|}{ Vertical } \\
\hline & Extinction & Absorption & Scattering & Extinction & Absorption & Scattering \\
\hline & \multicolumn{6}{|c|}{ Random Orientation } \\
\hline 10 & $3.083 \times 10^{-4}$ & $3.083 \times 10^{-4}$ & $1.741 \times 10^{-9}$ & $3.083 \times 10^{-4}$ & $3.083 \times 10^{-4}$ & $1.741 \times 10^{-9}$ \\
\hline 50 & $1.544 \times 10^{-3}$ & $1.543 \times 10^{-3}$ & $1.089 \times 10^{-6}$ & $1.544 \times 10^{-3}$ & $1.543 \times 10^{-3}$ & $1.089 \times 10^{-6}$ \\
\hline 100 & $3.116 \times 10^{-3}$ & $3.098 \times 10^{-3}$ & $1.744 \times 10^{-5}$ & $3.116 \times 10^{-3}$ & $3.098 \times 10^{-3}$ & $1.744 \times 10^{-5}$ \\
\hline 300 & $1.109 \times 10^{-2}$ & $9.662 \times 10^{-3}$ & $1.432 \times 10^{-3}$ & $1.109 \times 10^{-2}$ & $9.662 \times 10^{-3}$ & $1.432 \times 10^{-3}$ \\
\hline 500 & $2.867 \times 10^{-2}$ & $1.733 \times 10^{-2}$ & $1.134 \times 10^{-2}$ & $2.867 \times 10^{-2}$ & $1.733 \times 10^{-2}$ & $1.134 \times 10^{-2}$ \\
\hline 700 & $7.181 \times 10^{-2}$ & $2.683 \times 10^{-2}$ & $4.497 \times 10^{-2}$ & $7.181 \times 10^{-2}$ & $2.683 \times 10^{-2}$ & $4.497 \times 10^{-2}$ \\
\hline 1000 & $2.395 \times 10^{-1}$ & $4.572 \times 10^{-2}$ & $1.938 \times 10^{-1}$ & $2.395 \times 10^{-1}$ & $4.572 \times 10^{-2}$ & $1.938 \times 10^{-1}$ \\
\hline 1300 & $6.008 \times 10^{-1}$ & $7.033 \times 10^{-2}$ & $5.305 \times 10^{-1}$ & $6.008 \times 10^{-1}$ & $7.033 \times 10^{-2}$ & $5.305 \times 10^{-1}$ \\
\hline 5000 & 3.585 & $5.453 \times 10^{-1}$ & 3.040 & 3.585 & $5.454 \times 10^{-1}$ & 3.040 \\
\hline \multirow[t]{2}{*}{10000} & 1.945 & $5.824 \times 10^{-2}$ & 1.887 & 1.945 & $5.824 \times 10^{-2}$ & 1.887 \\
\hline & \multicolumn{6}{|c|}{ Nonrandom Orientation } \\
\hline 10 & $3.083 \times 10^{-4}$ & $3.083 \times 10^{-4}$ & $1.741 \times 10^{-9}$ & $3.083 \times 10^{-4}$ & $3.083 \times 10^{-4}$ & $1.741 \times 10^{-9}$ \\
\hline 50 & $1.545 \times 10^{-3}$ & $1.543 \times 10^{-3}$ & $1.089 \times 10^{-6}$ & $1.544 \times 10^{-3}$ & $1.543 \times 10^{-3}$ & $1.089 \times 10^{-6}$ \\
\hline 100 & $3.116 \times 10^{-3}$ & $3.099 \times 10^{-3}$ & $1.744 \times 10^{-5}$ & $3.116 \times 10^{-3}$ & $3.098 \times 10^{-3}$ & $1.744 \times 10^{-5}$ \\
\hline 300 & $1.112 \times 10^{-2}$ & $9.683 \times 10^{-3}$ & $1.435 \times 10^{-3}$ & $1.109 \times 10^{-2}$ & $9.662 \times 10^{-3}$ & $1.432 \times 10^{-3}$ \\
\hline 500 & $3.385 \times 10^{-2}$ & $1.744 \times 10^{-2}$ & $1.139 \times 10^{-2}$ & $2.867 \times 10^{-2}$ & $1.733 \times 10^{-2}$ & $1.134 \times 10^{-2}$ \\
\hline 700 & $7.258 \times 10^{-2}$ & $2.718 \times 10^{-2}$ & $4.540 \times 10^{-2}$ & $7.181 \times 10^{-2}$ & $2.683 \times 10^{-2}$ & $4.497 \times 10^{-2}$ \\
\hline 1000 & $2.449 \times 10^{-1}$ & $4.703 \times 10^{-2}$ & $1.978 \times 10^{-1}$ & $2.395 \times 10^{-1}$ & $4.573 \times 10^{-2}$ & $1.938 \times 10^{-1}$ \\
\hline 1300 & $6.236 \times 10^{-1}$ & $7.406 \times 10^{-2}$ & $5.495 \times 10^{-1}$ & $6.008 \times 10^{-1}$ & $7.035 \times 10^{-2}$ & $5.304 \times 10^{-1}$ \\
\hline 5000 & 2.999 & $8.760 \times 10^{-1}$ & 2.123 & 3.470 & $4.805 \times 10^{-1}$ & 2.989 \\
\hline 10000 & 2.216 & $2.244 \times 10^{-1}$ & 1.992 & 2.195 & $1.058 \times 10^{-1}$ & 2.090 \\
\hline
\end{tabular}

Size is the radius of the circumscribing sphere in $\mu \mathrm{m}$.

The modeled wavelength is $8,100 \mu \mathrm{m}$, equivalent to $37 \mathrm{GHz}$.

The refractive index of water ice is $1.74+0.0024 \mathrm{i}$. 
Table 2. Extinction, absorption, and scattering efficiency for randomly and nonrandomly oriented cylindrical snow crystals having both horizontal and vertical polarizations, as determined using a discrete dipole model.

\begin{tabular}{|c|c|c|c|c|c|c|}
\hline \multirow{2}{*}{$\begin{array}{c}\text { Polarization } \\
\text { Size }(\mu \mathrm{m})\end{array}$} & \multicolumn{3}{|c|}{ Horizontal } & \multicolumn{3}{|c|}{ Vertical } \\
\hline & Extinction & Absorption & Scattering & Extinction & Absorption & Scattering \\
\hline & \multicolumn{6}{|c|}{ Random Orientation } \\
\hline 10 & $2.890 \times 10^{-4}$ & $2.890 \times 10^{-4}$ & $1.619 \times 10^{-9}$ & $2.890 \times 10^{-4}$ & $2.890 \times 10^{-4}$ & $1.619 \times 10^{-9}$ \\
\hline 50 & $1.448 \times 10^{-3}$ & $1.447 \times 10^{-3}$ & $1.012 \times 10^{-6}$ & $1.448 \times 10^{-3}$ & $1.447 \times 10^{-3}$ & $1.012 \times 10^{-6}$ \\
\hline 100 & $2.920 \times 10^{-3}$ & $2.904 \times 10^{-3}$ & $1.619 \times 10^{-5}$ & $2.920 \times 10^{-3}$ & $2.904 \times 10^{-3}$ & $1.619 \times 10^{-5}$ \\
\hline 300 & $1.036 \times 10^{-2}$ & $9.049 \times 10^{-3}$ & $1.314 \times 10^{-3}$ & $1.036 \times 10^{-2}$ & $9.049 \times 10^{-3}$ & $1.314 \times 10^{-3}$ \\
\hline 500 & $2.634 \times 10^{-2}$ & $1.620 \times 10^{-2}$ & $1.015 \times 10^{-2}$ & $2.634 \times 10^{-2}$ & $1.620 \times 10^{-2}$ & $1.015 \times 10^{-2}$ \\
\hline 700 & $6.383 \times 10^{-2}$ & $2.498 \times 10^{-2}$ & $3.885 \times 10^{-2}$ & $6.383 \times 10^{-2}$ & $2.498 \times 10^{-2}$ & $3.885 \times 10^{-2}$ \\
\hline 1000 & $1.998 \times 10^{-1}$ & $4.259 \times 10^{-2}$ & $1.572 \times 10^{-1}$ & $1.998 \times 10^{-1}$ & $4.259 \times 10^{-2}$ & $1.572 \times 10^{-1}$ \\
\hline 1300 & $4.831 \times 10^{-1}$ & $6.835 \times 10^{-2}$ & $4.148 \times 10^{-1}$ & $4.831 \times 10^{-1}$ & $6.835 \times 10^{-2}$ & $4.148 \times 10^{-1}$ \\
\hline 5000 & 2.257 & $4.736 \times 10^{-1}$ & 1.783 & 2.257 & $4.736 \times 10^{-1}$ & 1.783 \\
\hline \multirow[t]{2}{*}{10000} & 2.024 & $1.366 \times 10^{-1}$ & 1.887 & 2.024 & $1.367 \times 10^{-1}$ & 1.887 \\
\hline & \multicolumn{6}{|c|}{ Nonrandom Orientation } \\
\hline 10 & $3.620 \times 10^{-4}$ & $3.620 \times 10^{-4}$ & $2.019 \times 10^{-9}$ & $2.890 \times 10^{-4}$ & $2.890 \times 10^{-4}$ & $1.619 \times 10^{-9}$ \\
\hline 50 & $1.814 \times 10^{-3}$ & $1.812 \times 10^{-3}$ & $1.262 \times 10^{-6}$ & $1.448 \times 10^{-3}$ & $1.447 \times 10^{-3}$ & $1.012 \times 10^{-6}$ \\
\hline 100 & $3.660 \times 10^{-3}$ & $3.640 \times 10^{-3}$ & $2.023 \times 10^{-5}$ & $2.920 \times 10^{-3}$ & $2.904 \times 10^{-3}$ & $1.621 \times 10^{-5}$ \\
\hline 300 & $1.306 \times 10^{-2}$ & $1.139 \times 10^{-2}$ & $1.667 \times 10^{-3}$ & $1.036 \times 10^{-2}$ & $9.033 \times 10^{-3}$ & $1.323 \times 10^{-3}$ \\
\hline 500 & $3.385 \times 10^{-2}$ & $2.057 \times 10^{-2}$ & $1.328 \times 10^{-2}$ & $2.645 \times 10^{-2}$ & $1.612 \times 10^{-3}$ & $1.034 \times 10^{-2}$ \\
\hline 700 & $8.537 \times 10^{-2}$ & $3.217 \times 10^{-2}$ & $5.319 \times 10^{-2}$ & $6.495 \times 10^{-2}$ & $2.475 \times 10^{-2}$ & $4.021 \times 10^{-2}$ \\
\hline 1000 & $2.895 \times 10^{-1}$ & $5.583 \times 10^{-2}$ & $2.337 \times 10^{-1}$ & $2.083 \times 10^{-1}$ & $4.153 \times 10^{-2}$ & $1.668 \times 10^{-1}$ \\
\hline 1300 & $7.344 \times 10^{-1}$ & $8.692 \times 10^{-2}$ & $6.475 \times 10^{-1}$ & $5.057 \times 10^{-1}$ & $6.368 \times 10^{-2}$ & $4.420 \times 10^{-1}$ \\
\hline 5000 & 2.989 & $7.422 \times 10^{-1}$ & 2.246 & 3.829 & $4.404 \times 10^{-1}$ & 3.388 \\
\hline 10000 & 2.639 & $2.938 \times 10^{-1}$ & 2.346 & 2.683 & $1.913 \times 10^{-1}$ & 2.491 \\
\hline
\end{tabular}

Size is the radius of the circumscribing sphere in $\mu \mathrm{m}$.

The modeled wavelength is $8,100 \mu \mathrm{m}$, equivalent to $37 \mathrm{GHz}$.

The refractive index of water ice is $1.74+0.0024 \mathrm{i}$. 
Table 3. Extinction, absorption, and scattering efficiency for randomly and nonrandomly oriented hexagonally prismatic snow crystals having both horizontal and vertical polarizations, as determined using a discrete dipole model.

\begin{tabular}{|c|c|c|c|c|c|c|}
\hline \multirow{2}{*}{$\begin{array}{c}\text { Polarization } \\
\text { Size }(\mu \mathrm{m})\end{array}$} & \multicolumn{3}{|c|}{ Horizontal } & \multicolumn{3}{|c|}{ Vertical } \\
\hline & Extinction & Absorption & Scattering & Extinction & Absorption & Scattering \\
\hline & \multicolumn{6}{|c|}{ Random Orientation } \\
\hline 10 & $3.443 \times 10^{-4}$ & $3.443 \times 10^{-4}$ & $1.920 \times 10^{-9}$ & $3.440 \times 10^{-4}$ & $3.440 \times 10^{-4}$ & $1.927 \times 10^{-9}$ \\
\hline 50 & $1.725 \times 10^{-3}$ & $1.723 \times 10^{-3}$ & $1.201 \times 10^{-6}$ & $1.723 \times 10^{-3}$ & $1.722 \times 10^{-3}$ & $1.205 \times 10^{-6}$ \\
\hline 100 & $3.479 \times 10^{-3}$ & $3.460 \times 10^{-3}$ & $1.924 \times 10^{-5}$ & $3.476 \times 10^{-3}$ & $3.457 \times 10^{-3}$ & $1.931 \times 10^{-5}$ \\
\hline 300 & $1.238 \times 10^{-2}$ & $1.079 \times 10^{-2}$ & $1.586 \times 10^{-3}$ & $1.237 \times 10^{-2}$ & $1.078 \times 10^{-2}$ & $1.590 \times 10^{-3}$ \\
\hline 500 & $3.202 \times 10^{-2}$ & $1.938 \times 10^{-2}$ & $1.264 \times 10^{-2}$ & $3.197 \times 10^{-2}$ & $1.932 \times 10^{-2}$ & $1.264 \times 10^{-2}$ \\
\hline 700 & $8.061 \times 10^{-2}$ & $3.003 \times 10^{-2}$ & $5.059 \times 10^{-2}$ & $8.029 \times 10^{-2}$ & $2.986 \times 10^{-2}$ & $5.043 \times 10^{-2}$ \\
\hline 1000 & $2.723 \times 10^{-1}$ & $5.103 \times 10^{-2}$ & $2.212 \times 10^{-1}$ & $2.691 \times 10^{-1}$ & $5.045 \times 10^{-2}$ & $2.187 \times 10^{-1}$ \\
\hline 1300 & $6.847 \times 10^{-1}$ & $7.689 \times 10^{-2}$ & $6.078 \times 10^{-1}$ & $6.700 \times 10^{-1}$ & $7.551 \times 10^{-2}$ & $5.945 \times 10^{-1}$ \\
\hline 5000 & 5.099 & $5.174 \times 10^{-1}$ & 4.582 & 5.290 & $4.633 \times 10^{-1}$ & 4.827 \\
\hline \multirow[t]{2}{*}{10000} & 3.265 & $3.100 \times 10^{-1}$ & 2.955 & 2.758 & $1.132 \times 10^{-1}$ & 2.645 \\
\hline & \multicolumn{6}{|c|}{ Nonrandom Orientation } \\
\hline 10 & $3.065 \times 10^{-4}$ & $3.065 \times 10^{-4}$ & $1.700 \times 10^{-9}$ & $3.440 \times 10^{-4}$ & $3.440 \times 10^{-4}$ & $1.927 \times 10^{-9}$ \\
\hline 50 & $1.535 \times 10^{-3}$ & $1.534 \times 10^{-3}$ & $1.063 \times 10^{-6}$ & $1.723 \times 10^{-3}$ & $1.722 \times 10^{-3}$ & $1.205 \times 10^{-6}$ \\
\hline 100 & $3.097 \times 10^{-3}$ & $3.080 \times 10^{-3}$ & $1.703 \times 10^{-5}$ & $3.477 \times 10^{-3}$ & $3.457 \times 10^{-3}$ & $1.930 \times 10^{-5}$ \\
\hline 300 & $1.100 \times 10^{-2}$ & $9.605 \times 10^{-3}$ & $1.396 \times 10^{-3}$ & $1.238 \times 10^{-2}$ & $1.079 \times 10^{-2}$ & $1.585 \times 10^{-3}$ \\
\hline 500 & $2.823 \times 10^{-2}$ & $1.723 \times 10^{-2}$ & $1.100 \times 10^{-2}$ & $3.193 \times 10^{-2}$ & $1.939 \times 10^{-2}$ & $1.254 \times 10^{-2}$ \\
\hline 700 & $7.001 \times 10^{-2}$ & $2.667 \times 10^{-2}$ & $4.335 \times 10^{-2}$ & $7.976 \times 10^{-2}$ & $3.006 \times 10^{-2}$ & $4.971 \times 10^{-2}$ \\
\hline 1000 & $2.300 \times 10^{-1}$ & $4.549 \times 10^{-2}$ & $1.845 \times 10^{-1}$ & $2.647 \times 10^{-1}$ & $5.128 \times 10^{-2}$ & $2.134 \times 10^{-1}$ \\
\hline 1300 & $5.712 \times 10^{-1}$ & $7.069 \times 10^{-2}$ & $5.005 \times 10^{-1}$ & $6.585 \times 10^{-1}$ & $7.887 \times 10^{-2}$ & $5.796 \times 10^{-1}$ \\
\hline 5000 & 3.529 & $7.962 \times 10^{-1}$ & 2.733 & 3.133 & $4.232 \times 10^{-1}$ & 2.710 \\
\hline 10000 & 2.568 & $2.228 \times 10^{-1}$ & 2.345 & 2.265 & $1.260 \times 10^{-1}$ & 2.139 \\
\hline
\end{tabular}

Size is the radius of the circumscribing sphere in $\mu \mathrm{m}$.

The modeled wavelength is $8,100 \mu \mathrm{m}$, equivalent to $37 \mathrm{GHz}$.

The refractive index of water ice is $1.74+0.0024 \mathrm{i}$. 


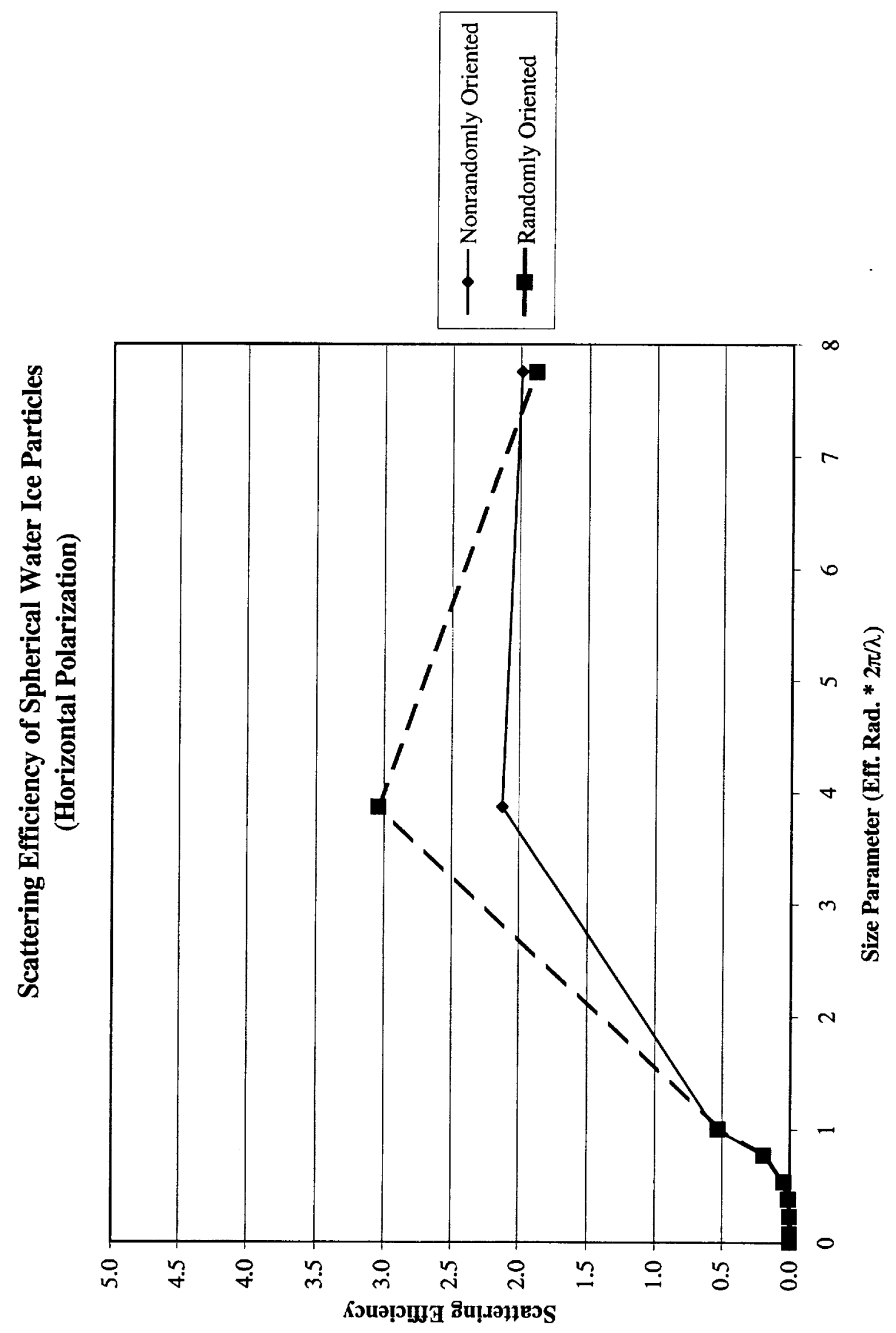



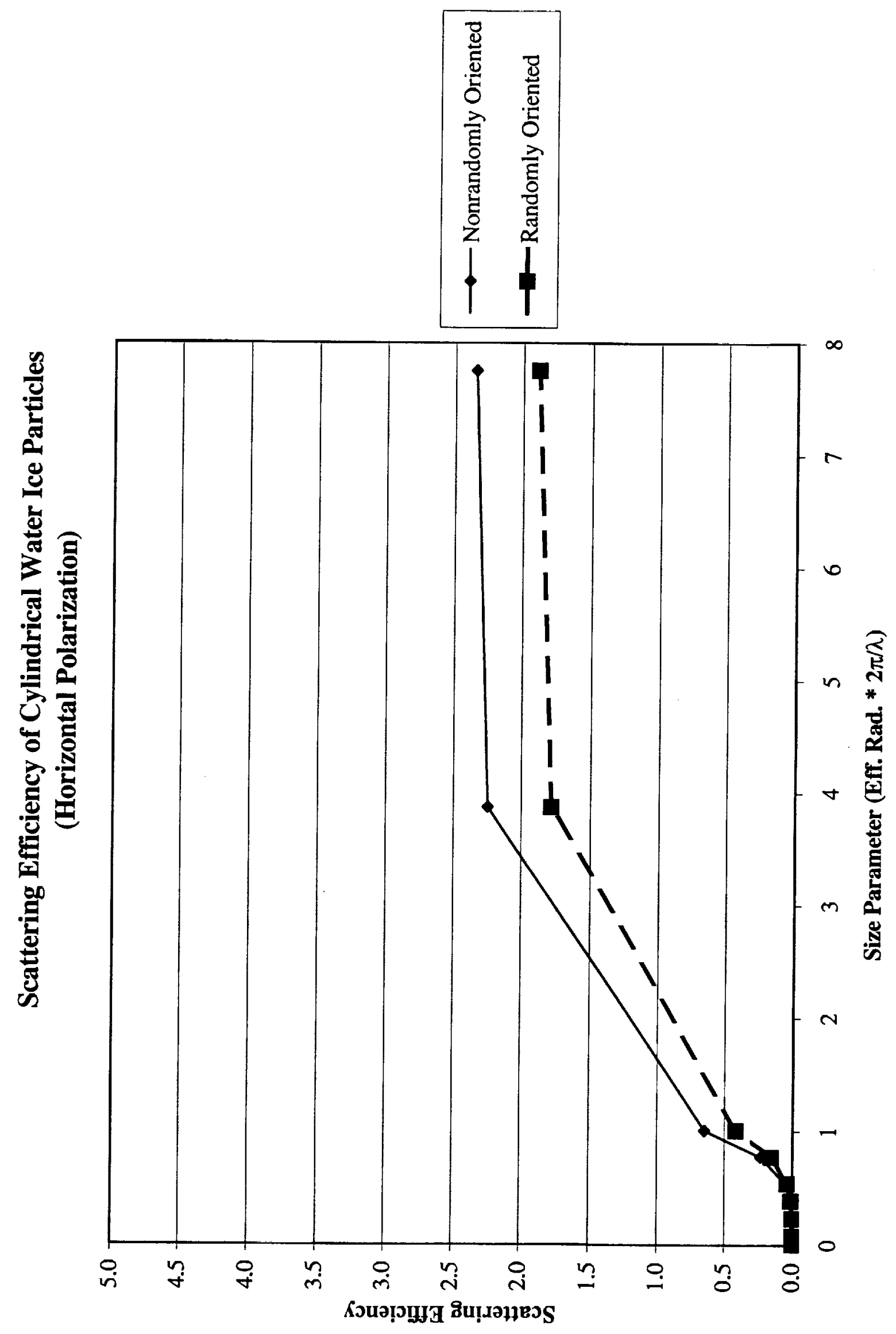


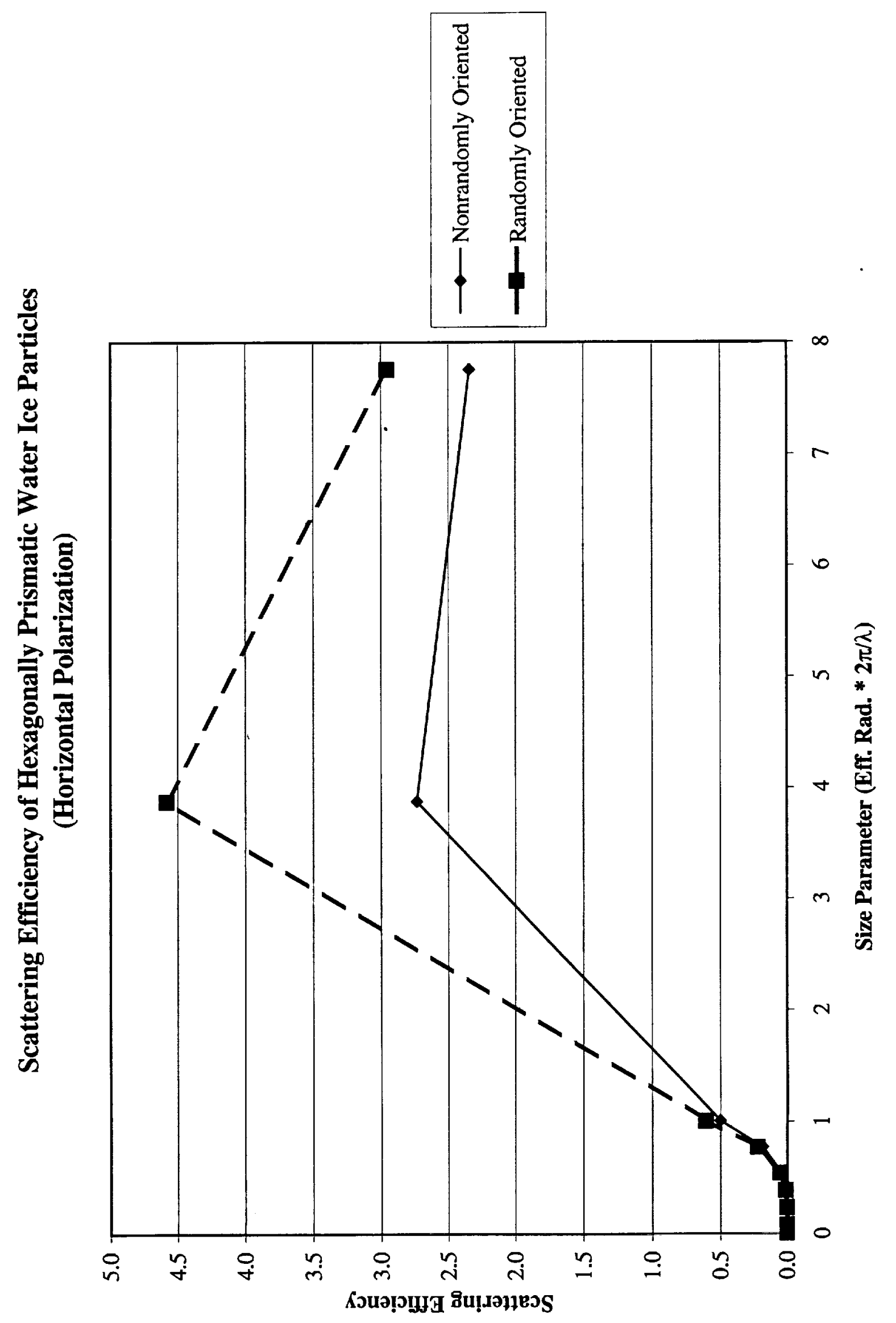




\title{
Snow Crystal Orientation Effects on the Scattering of Passive Microwave Radiation
}

\author{
J. L. Foster, J. S. Barton*, A. T. C. Chang, and D.K. Hall \\ NASA/Goddard Space Flight Center, Code 974 \\ Hydrological Sciences Branch \\ Laboratory for Hydrospheric Processes \\ Greenbelt, MD 20771 U.S.A \\ phone: 301-286-7096, fax: 301-286-1758 \\ e-mail: ifoster@glacier.gsfc.nasa.gov \\ *General Sciences Corporation, Greenbelt, MD 20770
}

\begin{abstract}
For this study, consideration is given to the role crystal orientation plays in scattering and absorbing microwave radiation. A discrete dipole scattering model is used to measure the passive microwave radiation, at two polariztions (horizontal and vertical), scattered by snow crystals oriented in random and non random positions, having various sizes (ranging between $1 \mu \mathrm{m}$ to $10,000 \mu \mathrm{m}$ in radius), and shapes (including spheroids, cylinders, hexagons). The model results demonstrate that for the crystal sizes typically found in a snowpack, crystal orientation is insignificant compared to crystal size in terms of scattering microwave energy in the $8,100 \mu \mathrm{m}$ $(37 \mathrm{GHz})$ region of the spectrum. Therefore, the assumption used in radiative transfer approaches, where snow crystals are modeled as randomly oriented spheres, is adequate to account for the transfer of microwave energy emanating from the ground and passing through a snowpack.
\end{abstract}

\section{Introduction}

Although snow and ice crystals may have a preferred orientation as they fall through the air on their way to the ground, once on the surface, their orientation with respect to a particular axis is most likely to be random. Processes such as sintering, compaction, and saltation act to prevent the crystals from being aligned in a like fashion. Nevertheless, because crystals within a given layer of the snowpack were formed and subsequently accumulated at nearly the same time, their physical characteristics, including their size, shape, density, and how they are oriented, are expected to be more similar to each other than they are to crystals in adjacent layers. 
Advances in particle scatter modeling and snow crystal collecting techniques have permitted much more detail to be learned about the physical characteristics of individual snow grains and about the redistribution of energy by these grains. By learning as much as we can about the physics of snow and how crystals interact with electromagnetic energy, we will be better able to accurately and reliably estimate the total area and volume of snow for a given drainage basin or climatic region. Knowing more about these values will then permit us to improve forecasts of snowmelt runoff and streamflow, and thus allow us to more confidently gage both the water and energy balance of a given area.

Although it is the volume of all of the snow crystals which is largely responsible for the microwave signal (Chang et al., 1976), it is not known whether or not the orientation of individual crystals has any effect on increasing the scattering or lessening the scattering of this signal. Most of the attention in algorithm development has been directed towards the effects of snow crystal size on scattering microwave energy, and some work has been devoted to the effects of crystal shape on microwave scattering (Foster et al., 1999). However, crystal size alone does not account for all of the scattering or energy redistribution.

Presently, a number of microwave algorithms are available to evaluate and retrieve snow cover and snow depth for specific regions and specific seasonal conditions. For the Chang et al. (1987) algorithm, the lack of precise information about snow crystal size and shape has been compensated for by using an average size of $0.3 \mathrm{~mm}$ (radius), a density of $300 \mathrm{~kg} \mathrm{~m}^{-3}$, an assumed spherical shape for the snow crystals, and the assumption that the crystals scatter 
radiation incoherently and independently of the path length between scattering centers (Chang et al., 1987). It has been demonstrated that if the snow crystal size differs significantly from the assumed average, then poor snow water equivalent (SWE) estimates will result (Chang et al., 1987; Foster et al., 1996). Furthermore, it has been found that the shape of the crystal plays no significant role in scattering microwave radiation (Foster et al., 1997; Foster et al., 1999). However, it has not been known whether a significant error is induced in solving the radiative transfer equations by making assumptions about the orientation of snow crystals in a mature snowpack.

This study is a follow up to the paper on the microwave response to snow crystal shape, which was published in this journal last year (Foster et al., 1999). For the present study, again a particle scattering model is used, but this time to calculate the extinction, scattering and absorption efficiency of crystals having random and non random orientations with both horizontal and vertical polarizations. This information will be valuable for determining whether the orientation of the snow crystal is an important enough parameter to be accounted for in modeling the radiative transfer of microwave energy emanating from below and within snowpacks.

\section{Passive Microwave Radiometry}

The microwave radiation emitted by a snow cover is dependent upon the physical temperature, crystal characteristics and the density of the snow. A basic relationship between these properties and the emitted radiation can be derived by using the radiative transfer approach. Microwave emission from a snow layer over a ground medium consists of contributions from the snow itself and from the underlying ground. Both contributions are governed by the transmission 
and reflection properties of the air-snow and snow-ground boundaries and by the absorption/emission and scattering properties of the snow layers (Foster et al., 1984). If the snowpack is thick (> penetration depth of the wavelength) then it may be treated as a semi-infinite medium and contributions from the ground will not be as important (Chang et al., 1976). Otherwise, volume scattering by the myriad of crystals is the primary mechanism for the redistribution of the emitted microwave energy.

As an electromagnetic wave emitted from the underlying ground propagates through the snowpack, it is scattered by the snow particles in all directions. Consequently, when the wave emerges at the snow/air interface, its amplitude has been attenuated. Dry snow absorbs very little microwave energy, and therefore it contributes very little in the form of self-emission (Ulaby and Stiles, 1981; Foster et al., 1984). Snow crystals are effective scatterers of microwave energy for frequencies greater than $\sim 20 \mathrm{GHz}$. The snow crystals scatter part of the cold sky radiation, which reduces the upwelling radiation measured with a radiometer (Schmugge, 1980). The deeper the snow, the more snow crystals are available to scatter the upwelling microwave energy, and thus it is possible to estimate the depth of the snow and the snow water equivalent. Absorption of microwave energy by dry snow crystals is very small, about $10^{6}$ times smaller than for water in the liquid phase (Ulaby and Stiles, 1981). With increasing free water in snow, and an accompanying increase in the dielectric constant, absorption will begin to dominate over scattering (Hallinkainen, 1989). 


\section{Modeling}

A discrete dipole model (Draine and Flatau, 1994) is used here to approximate the microwave scattering and absorption of an idealized snow crystal having two orientations; random and non random. In this experiment, spheroids, cylinders, and hexagons were modeled having an effective radius (radius of a sphere of equal volume) of $10 \mu \mathrm{m}, 50 \mu \mathrm{m}, 100 \mu \mathrm{m}, 300 \mu \mathrm{m}, 500 \mu \mathrm{m}, 700 \mu \mathrm{m}$, $1,000 \mu \mathrm{m}, 1,300 \mu \mathrm{m}, 5,000 \mu \mathrm{m}$, and 10,000 $\mu \mathrm{m}$. The discrete dipole scattering (DDSCAT) model employed here is a Fortran program that calculates scattering and absorption of electromagnetic radiation by arbitrary targets using the discrete dipole approximation (DDA). In this approximation, the targets are replaced by an array of point dipoles. See Draine (1988) and Foster et al. (1999) for more details concerning the DDSCAT model.

For this study, the wavelength selected was 8,100 microns $(0.81 \mathrm{~cm})$, corresponding to $37 \mathrm{GHz}$. Previous work has shown (Chang et al., 1987), that for snowpacks less than a meter in depth, more information about the SWE can be derived when using a frequency of about $37 \mathrm{GHz}$ than when using higher or lower frequencies. A refractive index of 1.78 is used for the real part of the refractive index of ice and 0.0024 is used for the imaginary part (the refractive index is the square root of the dielectric constant). The true thickness of a deposit is not required for emission boundary conditions; scattering or absorption results from the array of point dipoles.

The incident radiation is always assumed to propagate along the $\mathrm{x}$ axis. Two vectors ( $\mathrm{a} 1$ and $\mathrm{a} 2$ ) are assumed to be embedded within the target; a2 is perpendicular to a1. For the case of a $9 \times 6 \times$ 3 rectangular array, the vector a1 is along the long axis, and the vector a2 is along the intermediate axis. The target orientation is set by the angles BETA, THETA and PHI. The polar 
angles THETA and PHI specify the direction of al with respect to the incident radiation. The target is assumed to be rotated around al by an angle BETA. In this study, two cases were examined: a randomly oriented case, where BETA, THETA, and PHI are all allowed to vary between 0 and 360 degrees and the result is averaged over that range; a non random case, where BETA and PHI are held constant at $0^{\circ}$, and THETA is permitted to vary from $0-90^{\circ}$. The model allows for the specification of a general elliptical polarization for incident radiation. However, for this study, two linear polarizations, parallel to the horizontal and vertical axes, were used. Scattered intensities are computed for two scattering planes at intervals of 30 degrees in the scattering angle theta.; phi $=0$ for the $x-y$ plane, and phi $=90$ for the $x-z$ plane (Draine and Flatau, 1994)

\section{Results and Discussion}

Tables 1, 2 and 3 show extinction, absorption and scattering for non random as well as random crystal orientations (spheroids, cylinders and hexagonal prisms) having either horizontal or vertical polarizations. Figures 1, 2 and 3 (not shown here) present what the tables convey in graph form.

Looking at Table 1, for non randomly oriented and horizontally polarized crystals having an effective radius of $300 \mu \mathrm{m}$, and with the above BETA, THETA and PHI constraints, the average scattering is equal to $1.44 \times 10^{-3}$, the average absorption is equal to $9.68 \times 10^{-3}$, and the extinction efficiency is equal to $1.11 \times 10^{-2}$ ( $Q$ extinction $=\mathrm{Q}$ scattering $+\mathrm{Q}$ absorption). For the randomly oriented, horizontally polarized spheroids, scattering, absorption and extinction are 
$1.43 \times 10^{-3}, 9.66 \times 10^{-3}$ and $1.11 \times 10^{-2}$, respectively. There is virtually no difference between the randomly and non randomly oriented spherical crystals.

Looking at each of the three Tables, it can be observed that regardless of the size, the shape or the polarization of the crystal, only very small differences exist between the randomly and non randomly oriented crystals. For instance, when comparing the scattering of non randomly oriented spheres to cylinders, the amount of scattering is similar, no matter what the particle size. The cylinders scatter minutely more amounts of radiation than do the spheres. For randomly oriented crystals, the scattering differences between spheres and cylinders are even smaller. However, whereas for the non randomly oriented cylinders a slight difference exists in scattering between the $\mathrm{H}$ and $\mathrm{V}$ polarizations, there is no difference in scattering between the $\mathrm{H}$ and $\mathrm{V}$ polarizations for the randomly oriented cylinders. This is also true for the hexagonal prisms. Also, note that for each crystal shape, regardless of the orientation, the $\mathrm{V}$ polarization has the same scattering values for all but the largest crystal sizes.

It should be pointed out that for the largest crystals $(10,000 \mu \mathrm{m})$, extinction may actually decrease. This is because when the particle size is greater than the wavelength $(8100 \mu \mathrm{m})$, extinction no longer increases but rather oscillates (Ulaby et al., 1981). Calculations of the attenuation cross sections of large ice and water spheres have shown that the normalized attenuation cross section increases up to a size parameter $(\alpha)$ of 1 , and from there decreases to a size parameter of 5 (Atlas and Wexler, 1963; Battan, Browning and Herman, 1970). 
It is reasonable to expect that freshly fallen snow is more likely to have preferred crystal orientations than do older snow grains which due to settling, melt and refreezing have been repositioned. In some cases, the structure of the snowpack has been shown to exacerbate the differences between the vertically and horizontally polarized microwave data. For example, Hall et al. (1984) found that where the snowpack has undergone metamorphism, horizontally polarized data are better correlated to snow depth and SWE than are vertically polarized data. The vertically-polarized brightness temperatures at $37 \mathrm{GHz}$ for snow covered land has been shown to be more sensitive, or to vary more diurnally, than horizontally polarized brightness temperatures (Hallikainen, 1989). Walker and Goodison (1993) have used the polarization difference at $37 \mathrm{GHz}$ to discriminate wet snow from snow free land. Ice lenses and metamorphosed snow layers are horizontal media, which seem to influence vertically-polarized data more than the horizontally polarized data. From the tables, non randomly oriented crystals, do show small polarization differences compared to the randomly oriented crystals, but again, these modeled differences are very small.

For the visible wavelengths, how ice crystals are aligned as they fall through the air is strongly related to how light is refracted and reflected to an observer on the ground. Ice crystals may become oriented by aerodynamic forces as they fall through the atmosphere. If this happens, a collection of stellar plate crystals, for instance, is aligned with their faces (a axis) in a horizontal position to the ground while the plate edge is vertical (c axis). If sunlight passes symmetrically through the plane perpendicular to the refracting edge, minimum deviation will occur. The 22 degree minimum deviation of sunlight passing through the 60 degree prism of the hexagonally oriented plates will cause the light to be concentrated in a narrow range of angles, resulting in a 
parhelia or sundogs (bright spots on either side of the Sun, at least 22 degrees away). A grouping of these same plate crystals which show no preferred orientation will instead produce a 22 degree halo around the Sun (Lynch and Livingston, 1995).

With wavelengths longer than visible light, crystal orientation is not a key factor in terms of how much energy is scattered and absorbed in falling snow or in snow on the ground. For the crystal sizes typically found in a snowpack, the effective particle size is so dominant in scattering microwave radiation that the cumulative contribution of other structural features, including orientation, seems to be overwhelmed. Evidence for this has been presented in several studies (Siqueira, 1995, Matzler, 1997 and Foster et al., 1999). In refining the microwave algorithms used to estimated snow depth and SWE, it is necessary to have accurate measurements and or models that consider the effects of all possible sources in scattering and absorbing microwave energy. It is important to know which contributions are critical and which can be ignored. The results presented here using a discrete dipole model show that for scattering, the crystal orientation can be ignored, in terms of the extinction of microwave energy.

Nevertheless, it needs to be remembered that models are only representations which can be used to direct experiments, but their accuracy cannot actually be proved, only disproved (Oreskes, 1994). The mathematical representations are only approximate descriptions of actual processes because the processes are so complex and are based on observations which themselves contain uncertainties. Even if the solutions seem reasonable and reproducible, this does not mean that they are correct. This being said, the discrete dipole model has been consistent with a number of 
physical observations, crystal size and microwave scattering for instance. Thus, this model can be more confidently used to evaluate snow crystal orientation effects and microwave scattering.

\section{Conclusions and Future Plans}

While effective crystal size is strongly related to microwave brightness temperature, it appears from the modeling results of this study that the orientation of snow crystals has a negligible effect in accounting for the transfer of microwave radiation (at $8,100 \mu \mathrm{m})$ from the ground through the snowpack. Furthermore, regardless of the shape of the crystal (spheroid, cylinder or hexagonal prism), the polarization effects are only slightly greater for non randomly oriented crystals than for randomly oriented crystals. Thus, the assumption used in radiative transfer approaches, where snow crystals are modeled as randomly oriented spheres, is adequate to account for the transfer of microwave energy emanating from the ground and passing through a snowpack.

\section{References}

Armstrong, R., A. Chang, A. Rango, and E. Josberger, "Snow depth and grain size relationships with relevance for passive microwave studies" Annals of Glaciology, Vol. 17, 171-176, 1993.

Chang, A. T. C., P. Gloersen, T. Schmugge, T. Wilheit, and H. J. Zwally, "Microwave emission from snow and glacier ice" Journal of Glaciology, Vol. 16, 23-39, 1976.

Chang, A.T.C., J.L. Foster and D.K.Hall, "Nimbus-7 SMMR derived global snow cover parameters" Annals of Glaciology, Vol. 9, 39-44, 1987. 
Draine, B., "The discrete dipole approximation and its application to interstellar graphite grains," Joumal of Astrophysics, Vol. 33, 848-872, 1988.

Draine, B. and P. Flatau, "Discrete dipole approximation for scattering calculations," Journal of the American Optical Society, Vol. 11, 1491-1499, 1994.

Foster, J. L., D. K. and A. T. C. Chang, "An overview of passive microwave snow research and results" Reviews of Geophysics and Space Physics Vol. 22, 195-208, 1984.

Foster, J., D.Hall, A. Chang, A. Rango, W. Wergin, and E. Erbe, "Observations of snow crystal shape in cold snowpacks using scanning electron microscopy," Proceedings of the IGARSS 1996, Vol. 4, 2011-2013, Lincoln, NE, 1996.

Foster, J., D. Hall, A. Chang, A. Rango, W. Wergin, and E. Erbe, "Snow crystal shape and microwave scattering" Proceedings of the IGARSS 1997, Vol. 2, 625-627, Singapore, 1997.

Foster, J., A. Chang, D. Hall, A. Rango, W. Wergin, and E. Erbe, "Effects of snow crystal shape on passive microwave radiation" Transactions of Geoscience and Remote Sensing (IEEE) (in press).

Goodman, J., B. Draine, and P. Flatau, "Applications of FFT techniques to the discrete dipole approximation," Optical Letters, Vol. 16, 1198-1200, 1991. 
Hall, D. K., A. T. C. Chang, and J. L. Foster, " Polarization responses to snow depth in the midwestern U. S. " Nordic Hydrology, Vol. 15, 1-8, 1984.

Hallikainen, M., "Microwave radiometry of snow" Advanced Space Research, Vol. 9, No. 1, 267-275, 1989.

Lynch, D. and W. Livingston, Color and Light in Nature , Cambridge University Press, NY, 152-166, 1995.

Matzler, C., "Autocorrelation functions of granular media with arrangement of spheres, spherical shells or ellipsoids" Journal of Applied Physics, Vol. 3, 1509-1517, 1997.

Oreskes, N., K. Shrader-Frechette and K. Belitz, 1994: "Verification, validation and confirmation of numerical models in the earth sciences" Science, Vol. 23, 762-767.

Schmugge, T., "Techniques and applications of microwave radiometry" in Remote Sensing of Geology, edited by B. Siegal and A. Gillespie, John Wiley, New York, Chapter 11, 337-352, 1980.

Siqueira. P. R., K. Sarabandi and F. T. Ulaby, "Numerical simulation of scatterer positions in a very dense medium with an application to the two-dimensional Born approximation" Radio Science, Vol. 30, Number 5, 1325-1338, 1995. 
Ulaby, F. T. and W. H. Stiles, 'The active and passive microwave response to snow parameters" Journal of Geophysical Research, Vol. 85, 1045-1049, 1981.

Ulaby, F. T., K. Moore, and A. K. Fung,, Microwave remote sensing: active and passive, Vol. III, Adison-Wesle Publication Co, 1986

Walker, A. E. and B. E. Goodison, "Discrimination of a wet snow cover using passive microwave satellite data" Annals of Glaciology, Vol. 17, 307-311. 


\section{List of Tables}

Table 1 - Extinction, scattering and absorption efficiency for randomly and non randomly oriented spheroid snow crystals having both horizontal and vertical polarizations, as determined using a discrete dipole model.

Table 2 - Same as Table 1 except for cylindrical crystals.

Table 3 - Same as Table 1 except for hexagonal prisms.

\section{List of Figures}

Figure 1 - Plot showing scattering efficiency of spherical water ice particles having both random and non random orientation.

Figure 2 - Same as Figure 1, except for cylindrical particles.

Figure 3 - Same as Figure 1 and 2, except for hexagonal particles. 
Table 1. Extinction, absorption, and scattering efficiency for randomly and nonrandomly oriented spherical snow crystals having both horizontal and vertical polarizations, as determined using a discrete dipole model.

\begin{tabular}{|c|c|c|c|c|c|c|}
\hline \multirow{2}{*}{$\begin{array}{c}\text { Polarization } \\
\text { Size }(\mu \mathrm{m}) \\
\end{array}$} & \multicolumn{3}{|c|}{ Horizontal } & \multicolumn{3}{|c|}{ Vertical } \\
\hline & Extinction & Absorption & Scattering & Extinction & Absorption & Scattering \\
\hline & \multicolumn{6}{|c|}{ Random Orientation } \\
\hline 10 & $3.083 \times 10^{-4}$ & $3.083 \times 10^{-4}$ & $1.741 \times 10^{-9}$ & $3.083 \times 10^{.4}$ & $3.083 \times 10^{-4}$ & $1.741 \times 10^{-9}$ \\
\hline 50 & $1.544 \times 10^{-3}$ & $1.543 \times 10^{-3}$ & $1.089 \times 10^{-6}$ & $1.544 \times 10^{-3}$ & $1.543 \times 10^{-3}$ & $1.089 \times 10^{-6}$ \\
\hline 100 & $3.116 \times 10^{-3}$ & $3.098 \times 10^{-3}$ & $1.744 \times 10^{-5}$ & $3.116 \times 10^{-3}$ & $3.098 \times 10^{-3}$ & $1.744 \times 10^{-5}$ \\
\hline 300 & $1.109 \times 10^{-2}$ & $9.662 \times 10^{-3}$ & $1.432 \times 10^{-3}$ & $1.109 \times 10^{-2}$ & $9.662 \times 10^{-3}$ & $1.432 \times 10^{-3}$ \\
\hline 500 & $2.867 \times 10^{-2}$ & $1.733 \times 10^{-2}$ & $1.134 \times 10^{-2}$ & $2.867 \times 10^{-2}$ & $1.733 \times 10^{-2}$ & $1.134 \times 10^{-2}$ \\
\hline 700 & $7.181 \times 10^{-2}$ & $2.683 \times 10^{-2}$ & $4.497 \times 10^{-2}$ & $7.181 \times 10^{-2}$ & $2.683 \times 10^{-2}$ & $4.497 \times 10^{-2}$ \\
\hline 1000 & $2.395 \times 10^{-1}$ & $4.572 \times 10^{-2}$ & $1.938 \times 10^{-1}$ & $2.395 \times 10^{-1}$ & $4.572 \times 10^{-2}$ & $1.938 \times 10^{-1}$ \\
\hline 1300 & $6.008 \times 10^{-1}$ & $7.033 \times 10^{-2}$ & $5.305 \times 10^{-1}$ & $6.008 \times 10^{-1}$ & $7.033 \times 10^{-2}$ & $5.305 \times 10^{-1}$ \\
\hline 5000 & 3.585 & $5.453 \times 10^{-1}$ & 3.040 & 3.585 & $5.454 \times 10^{-1}$ & 3.040 \\
\hline \multirow[t]{2}{*}{10000} & 1.945 & $5.824 \times 10^{-2}$ & 1.887 & 1.945 & $5.824 \times 10^{-2}$ & 1.887 \\
\hline & \multicolumn{6}{|c|}{ Nonrandom Orientation } \\
\hline 10 & $3.083 \times 10^{-4}$ & $3.083 \times 10^{-4}$ & $1.741 \times 10^{-9}$ & $3.083 \times 10^{-4}$ & $3.083 \times 10^{-4}$ & $1.741 \times 10^{-9}$ \\
\hline 50 & $1.545 \times 10^{-3}$ & $1.543 \times 10^{-3}$ & $1.089 \times 10^{-6}$ & $1.544 \times 10^{-3}$ & $1.543 \times 10^{-3}$ & $1.089 \times 10^{-6}$ \\
\hline 100 & $3.116 \times 10^{-3}$ & $3.099 \times 10^{-3}$ & $1.744 \times 10^{-5}$ & $3.116 \times 10^{-3}$ & $3.098 \times 10^{-3}$ & $1.744 \times 10^{-5}$ \\
\hline 300 & $1.112 \times 10^{-2}$ & $9.683 \times 10^{-3}$ & $1.435 \times 10^{-3}$ & $1.109 \times 10^{-2}$ & $9.662 \times 10^{-3}$ & $1.432 \times 10^{-3}$ \\
\hline 500 & $3.385 \times 10^{-2}$ & $1.744 \times 10^{-2}$ & $1.139 \times 10^{-2}$ & $2.867 \times 10^{-2}$ & $1.733 \times 10^{-2}$ & $1.134 \times 10^{-2}$ \\
\hline 700 & $7.258 \times 10^{-2}$ & $2.718 \times 10^{-2}$ & $4.540 \times 10^{-2}$ & $7.181 \times 10^{-2}$ & $2.683 \times 10^{-2}$ & $4.497 \times 10^{-2}$ \\
\hline 1000 & $2.449 \times 10^{-1}$ & $4.703 \times 10^{-2}$ & $1.978 \times 10^{-1}$ & $2.395 \times 10^{-1}$ & $4.573 \times 10^{-2}$ & $1.938 \times 10^{-1}$ \\
\hline 1300 & $6.236 \times 10^{-1}$ & $7.406 \times 10^{-2}$ & $5.495 \times 10^{-1}$ & $6.008 \times 10^{-1}$ & $7.035 \times 10^{-2}$ & $5.304 \times 10^{-1}$ \\
\hline 5000 & 2.999 & $8.760 \times 10^{-1}$ & 2.123 & 3.470 & $4.805 \times 10^{-1}$ & 2.989 \\
\hline 10000 & 2.216 & $2.244 \times 10^{-1}$ & 1.992 & 2.195 & $1.058 \times 10^{-1}$ & 2.090 \\
\hline
\end{tabular}

Size is the radius of the circumscribing sphere in $\mu \mathrm{m}$.

The modeled wavelength is $8,100 \mu \mathrm{m}$, equivalent to $37 \mathrm{GHz}$.

The refractive index of water ice is $1.74+0.0024 \mathrm{i}$. 
Table 2. Extinction, absorption, and scattering efficiency for randomly and nonrandomly oriented cylindrical snow crystals having both horizontal and vertical polarizations, as determined using a discrete dipole model.

\begin{tabular}{|c|c|c|c|c|c|c|}
\hline \multirow{2}{*}{$\begin{array}{c}\text { Polarization } \\
\text { Size }(\mu \mathrm{m}) \\
\end{array}$} & \multicolumn{3}{|c|}{ Horizontal } & \multicolumn{3}{|c|}{ Vertical } \\
\hline & Extinction & Absorption & Scattering & Extinction & Absorption & Scattering \\
\hline & \multicolumn{6}{|c|}{ Random Orientation } \\
\hline 10 & $2.890 \times 10^{-4}$ & $2.890 \times 10^{-4}$ & $1.619 \times 10^{-9}$ & $2.890 \times 10^{-4}$ & $2.890 \times 10^{-4}$ & $1.619 \times 10^{-9}$ \\
\hline 50 & $1.448 \times 10^{-3}$ & $1.447 \times 10^{-3}$ & $1.012 \times 10^{-6}$ & $1.448 \times 10^{-3}$ & $1.447 \times 10^{-3}$ & $1.012 \times 10^{-6}$ \\
\hline 100 & $2.920 \times 10^{-3}$ & $2.904 \times 10^{-3}$ & $1.619 \times 10^{-5}$ & $2.920 \times 10^{-3}$ & $2.904 \times 10^{-3}$ & $1.619 \times 10^{-5}$ \\
\hline 300 & $1.036 \times 10^{-2}$ & $9.049 \times 10^{-3}$ & $1.314 \times 10^{-3}$ & $1.036 \times 10^{-2}$ & $9.049 \times 10^{-3}$ & $1.314 \times 10^{-3}$ \\
\hline 500 & $2.634 \times 10^{-2}$ & $1.620 \times 10^{-2}$ & $1.015 \times 10^{-2}$ & $2.634 \times 10^{-2}$ & $1.620 \times 10^{-2}$ & $1.015 \times 10^{-2}$ \\
\hline 700 & $6.383 \times 10^{-2}$ & $2.498 \times 10^{-2}$ & $3.885 \times 10^{-2}$ & $6.383 \times 10^{-2}$ & $2.498 \times 10^{-2}$ & $3.885 \times 10^{-2}$ \\
\hline 1000 & $1.998 \times 10^{-1}$ & $4.259 \times 10^{-2}$ & $1.572 \times 10^{-1}$ & $1.998 \times 10^{-1}$ & $4.259 \times 10^{-2}$ & $1.572 \times 10^{-1}$ \\
\hline 1300 & $4.831 \times 10^{-1}$ & $6.835 \times 10^{-2}$ & $4.148 \times 10^{-1}$ & $4.831 \times 10^{-1}$ & $6.835 \times 10^{-2}$ & $4.148 \times 10^{-1}$ \\
\hline 5000 & 2.257 & $4.736 \times 10^{-1}$ & 1.783 & 2.257 & $4.736 \times 10^{-1}$ & 1.783 \\
\hline \multirow[t]{2}{*}{10000} & 2.024 & $1.366 \times 10^{-1}$ & 1.887 & 2.024 & $1.367 \times 10^{-1}$ & 1.887 \\
\hline & \multicolumn{6}{|c|}{ Nonrandom Orientation } \\
\hline 10 & $3.620 \times 10^{-4}$ & $3.620 \times 10^{-4}$ & $2.019 \times 10^{-9}$ & $2.890 \times 10^{-4}$ & $2.890 \times 10^{-4}$ & $1.619 \times 10^{-9}$ \\
\hline 50 & $1.814 \times 10^{-3}$ & $1.812 \times 10^{-3}$ & $1.262 \times 10^{-6}$ & $1.448 \times 10^{-3}$ & $1.447 \times 10^{-3}$ & $1.012 \times 10^{-6}$ \\
\hline 100 & $3.660 \times 10^{-3}$ & $3.640 \times 10^{-3}$ & $2.023 \times 10^{-5}$ & $2.920 \times 10^{-3}$ & $2.904 \times 10^{-3}$ & $1.621 \times 10^{-5}$ \\
\hline 300 & $1.306 \times 10^{-2}$ & $1.139 \times 10^{-2}$ & $1.667 \times 10^{-3}$ & $1.036 \times 10^{-2}$ & $9.033 \times 10^{-3}$ & $1.323 \times 10^{-3}$ \\
\hline 500 & $3.385 \times 10^{-2}$ & $2.057 \times 10^{-2}$ & $1.328 \times 10^{-2}$ & $2.645 \times 10^{-2}$ & $1.612 \times 10^{-3}$ & $1.034 \times 10^{-2}$ \\
\hline 700 & $8.537 \times 10^{-2}$ & $3.217 \times 10^{-2}$ & $5.319 \times 10^{-2}$ & $6.495 \times 10^{-2}$ & $2.475 \times 10^{-2}$ & $4.021 \times 10^{-2}$ \\
\hline 1000 & $2.895 \times 10^{-1}$ & $5.583 \times 10^{-2}$ & $2.337 \times 10^{-1}$ & $2.083 \times 10^{-1}$ & $4.153 \times 10^{-2}$ & $1.668 \times 10^{-1}$ \\
\hline 1300 & $7.344 \times 10^{-1}$ & $8.692 \times 10^{-2}$ & $6.475 \times 10^{-1}$ & $5.057 \times 10^{-1}$ & $6.368 \times 10^{-2}$ & $4.420 \times 10^{-1}$ \\
\hline 5000 & 2.989 & $7.422 \times 10^{-1}$ & 2.246 & 3.829 & $4.404 \times 10^{-1}$ & 3.388 \\
\hline 10000 & 2.639 & $2.938 \times 10^{-1}$ & 2.346 & 2.683 & $1.913 \times 10^{-1}$ & 2.491 \\
\hline
\end{tabular}

Size is the radius of the circumscribing sphere in $\mu \mathrm{m}$.

The modeled wavelength is $8,100 \mu \mathrm{m}$, equivalent to $37 \mathrm{GHz}$.

The refractive index of water ice is $1.74+0.0024 \mathrm{i}$. 
Table 3. Extinction, absorption, and scattering efficiency for randomly and nonrandomly oriented hexagonally prismatic snow crystals having both horizontal and vertical polarizations, as determined using a discrete dipole model.

\begin{tabular}{|c|c|c|c|c|c|c|}
\hline Polarization & & Horizontal & & & Vertical & \\
\hline $\operatorname{Size}(\mu \mathrm{m})$ & Extinction & Absorption & Scattering & Extinction & Absorption & Scattering \\
\hline & \multicolumn{6}{|c|}{ Random Orientation } \\
\hline 10 & $3.443 \times 10^{-4}$ & $3.443 \times 10^{-4}$ & $1.920 \times 10^{-9}$ & $3.440 \times 10^{-4}$ & $3.440 \times 10^{-4}$ & $1.927 \times 10^{-9}$ \\
\hline 50 & $1.725 \times 10^{-3}$ & $1.723 \times 10^{-3}$ & $1.201 \times 10^{-6}$ & $1.723 \times 10^{-3}$ & $1.722 \times 10^{-3}$ & $1.205 \times 10^{-6}$ \\
\hline 100 & $3.479 \times 10^{-3}$ & $3.460 \times 10^{-3}$ & $1.924 \times 10^{-5}$ & $3.476 \times 10^{-3}$ & $3.457 \times 10^{-3}$ & $1.931 \times 10^{-5}$ \\
\hline 300 & $1.238 \times 10^{-2}$ & $1.079 \times 10^{-2}$ & $1.586 \times 10^{-3}$ & $1.237 \times 10^{-2}$ & $1.078 \times 10^{-2}$ & $1.590 \times 10^{-3}$ \\
\hline 500 & $3.202 \times 10^{-2}$ & $1.938 \times 10^{-2}$ & $1.264 \times 10^{-2}$ & $3.197 \times 10^{-2}$ & $1.932 \times 10^{-2}$ & $1.264 \times 10^{-2}$ \\
\hline 700 & $8.061 \times 10^{-2}$ & $3.003 \times 10^{-2}$ & $5.059 \times 10^{-2}$ & $8.029 \times 10^{-2}$ & $2.986 \times 10^{-2}$ & $5.043 \times 10^{-2}$ \\
\hline 1000 & $2.723 \times 10^{-1}$ & $5.103 \times 10^{-2}$ & $2.212 \times 10^{-1}$ & $2.691 \times 10^{-1}$ & $5.045 \times 10^{-2}$ & $2.187 \times 10^{-1}$ \\
\hline 1300 & $6.847 \times 10^{-1}$ & $7.689 \times 10^{-2}$ & $6.078 \times 10^{-1}$ & $6.700 \times 10^{-1}$ & $7.551 \times 10^{-2}$ & $5.945 \times 10^{-1}$ \\
\hline 5000 & 5.099 & $5.174 \times 10^{-1}$ & 4.582 & 5.290 & $4.633 \times 10^{-1}$ & 4.827 \\
\hline \multirow[t]{2}{*}{10000} & 3.265 & $3.100 \times 10^{-1}$ & 2.955 & 2.758 & $1.132 \times 10^{-1}$ & 2.645 \\
\hline & \multicolumn{6}{|c|}{ Nonrandom Orientation } \\
\hline 10 & $3.065 \times 10^{-4}$ & $3.065 \times 10^{-4}$ & $1.700 \times 10^{-9}$ & $3.440 \times 10^{-4}$ & $3.440 \times 10^{-4}$ & $1.927 \times 10^{-9}$ \\
\hline 50 & $1.535 \times 10^{-3}$ & $1.534 \times 10^{-3}$ & $1.063 \times 10^{-6}$ & $1.723 \times 10^{-3}$ & $1.722 \times 10^{-3}$ & $1.205 \times 10^{-6}$ \\
\hline 100 & $3.097 \times 10^{-3}$ & $3.080 \times 10^{-3}$ & $1.703 \times 10^{-5}$ & $3.477 \times 10^{-3}$ & $3.457 \times 10^{-3}$ & $1.930 \times 10^{-5}$ \\
\hline 300 & $1.100 \times 10^{-2}$ & $9.605 \times 10^{-3}$ & $1.396 \times 10^{-3}$ & $1.238 \times 10^{-2}$ & $1.079 \times 10^{-2}$ & $1.585 \times 10^{-3}$ \\
\hline 500 & $2.823 \times 10^{-2}$ & $1.723 \times 10^{-2}$ & $1.100 \times 10^{-2}$ & $3.193 \times 10^{-2}$ & $1.939 \times 10^{-2}$ & $1.254 \times 10^{-2}$ \\
\hline 700 & $7.001 \times 10^{-2}$ & $2.667 \times 10^{-2}$ & $4.335 \times 10^{-2}$ & $7.976 \times 10^{-2}$ & $3.006 \times 10^{-2}$ & $4.971 \times 10^{-2}$ \\
\hline 1000 & $2.300 \times 10^{-1}$ & $4.549 \times 10^{-2}$ & $1.845 \times 10^{-1}$ & $2.647 \times 10^{-1}$ & $5.128 \times 10^{-2}$ & $2.134 \times 10^{-1}$ \\
\hline 1300 & $5.712 \times 10^{-1}$ & $7.069 \times 10^{-2}$ & $5.005 \times 10^{-1}$ & $6.585 \times 10^{-1}$ & $7.887 \times 10^{-2}$ & $5.796 \times 10^{-1}$ \\
\hline 5000 & 3.529 & $7.962 \times 10^{-1}$ & 2.733 & 3.133 & $4.232 \times 10^{-1}$ & 2.710 \\
\hline 10000 & 2.568 & $2.228 \times 10^{-1}$ & 2.345 & 2.265 & $1.260 \times 10^{-1}$ & 2.139 \\
\hline
\end{tabular}

Size is the radius of the circumscribing sphere in $\mu \mathrm{m}$.

The modeled wavelength is $8,100 \mu \mathrm{m}$, equivalent to $37 \mathrm{GHz}$.

The refractive index of water ice is $1.74+0.0024 \mathrm{i}$. 


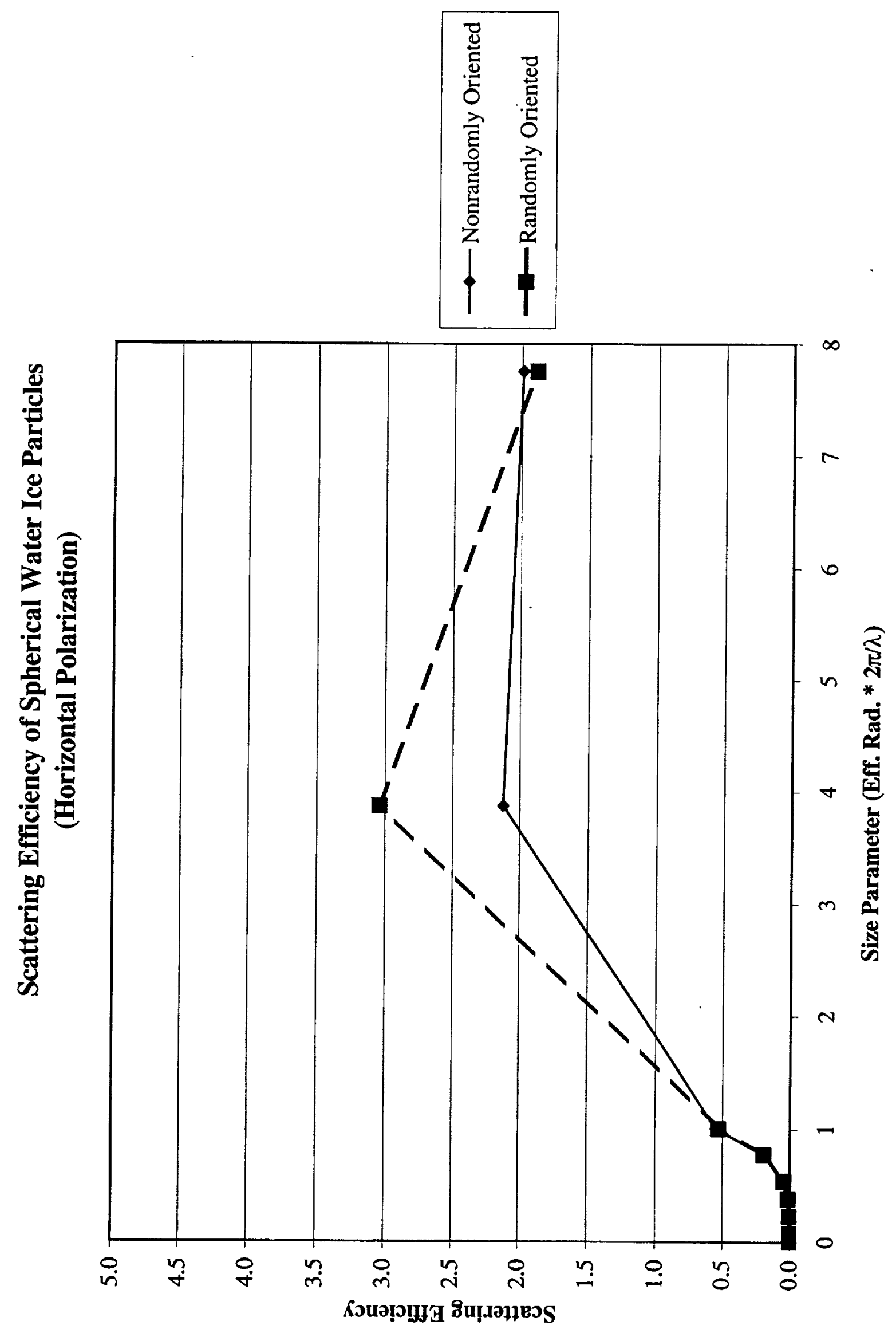



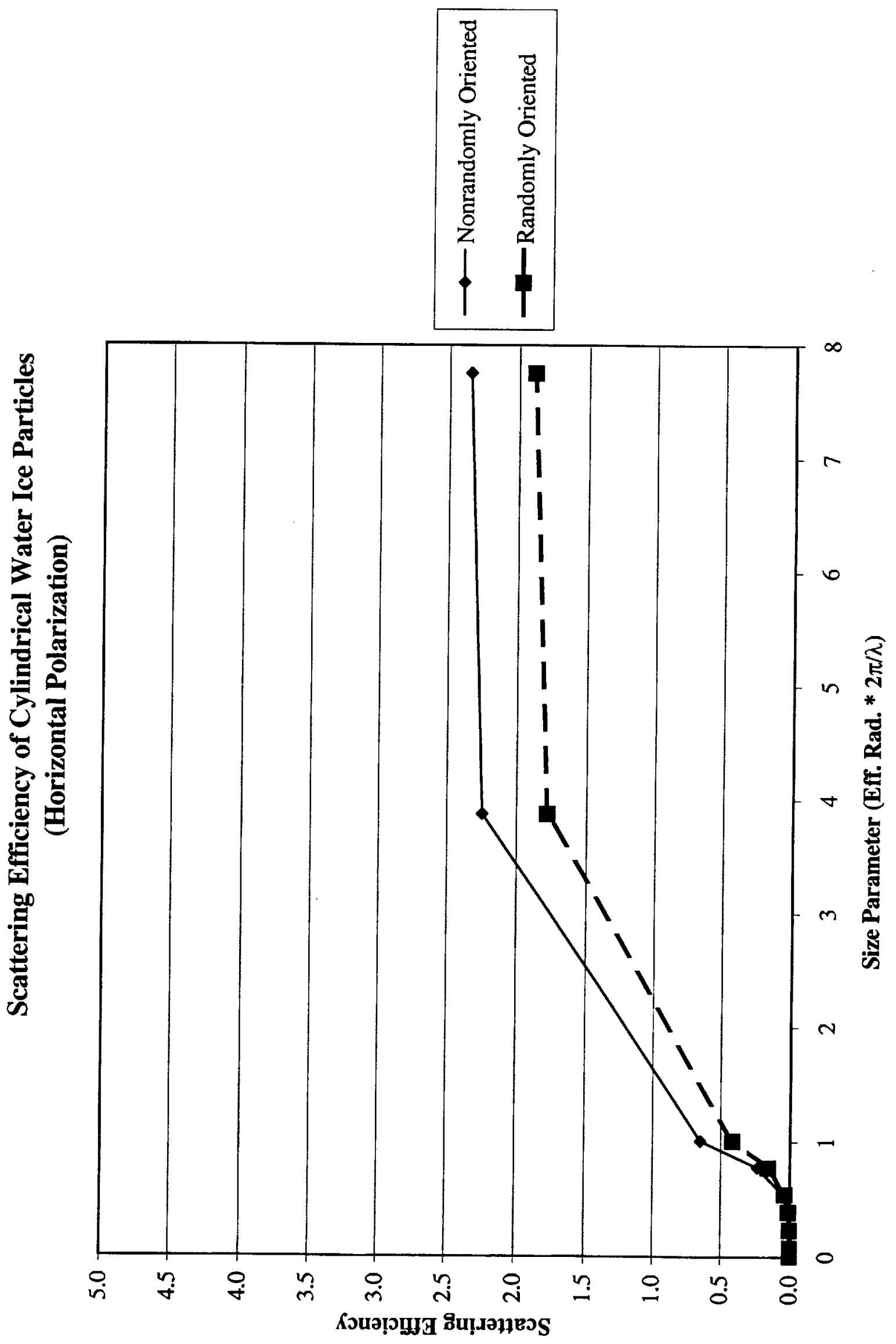


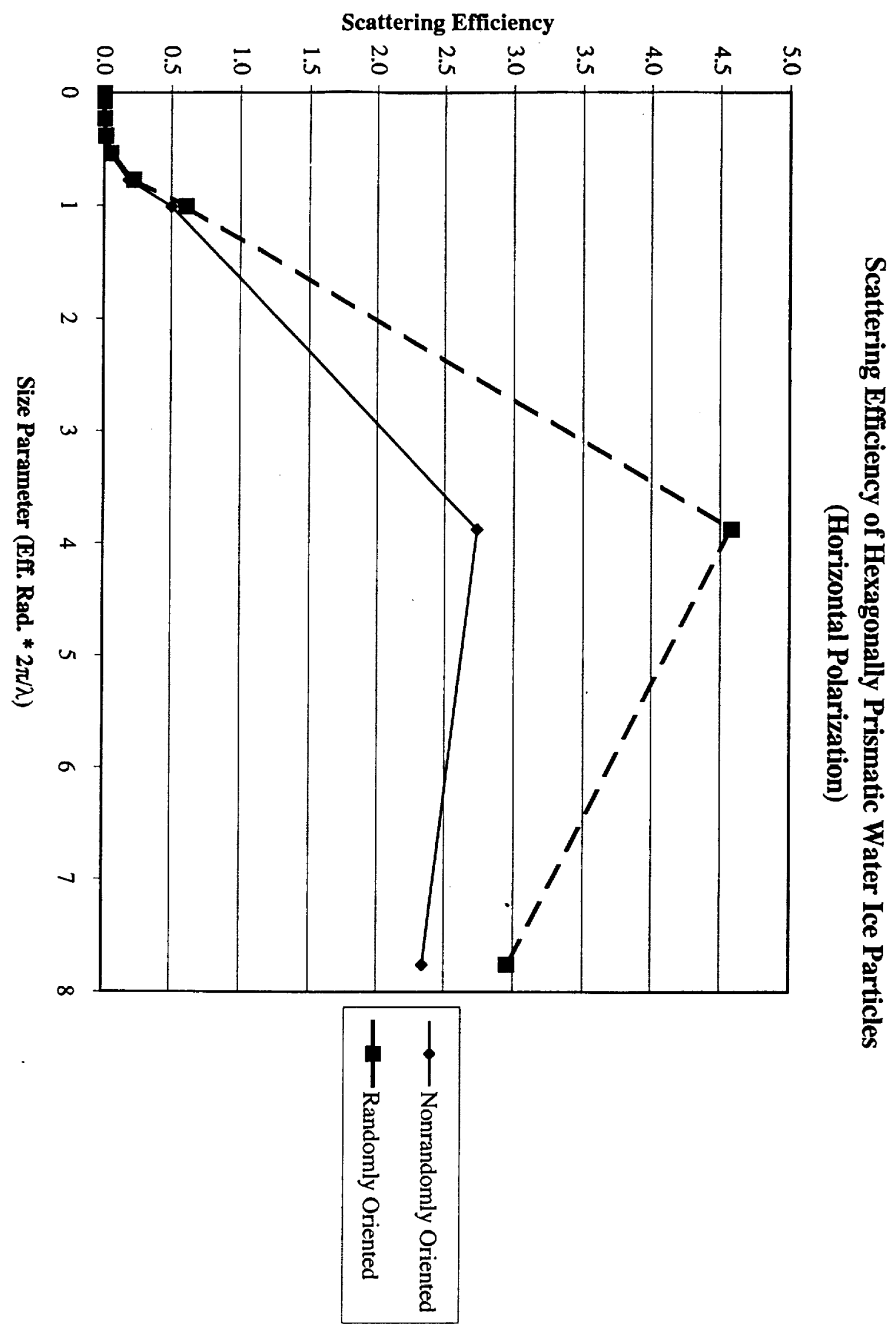

